\title{
Comparison of admission rates among patients treated by male and female emergency physicians: a multicenter study
}

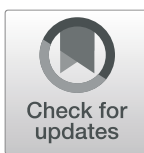

Hisham Valiuddin ${ }^{1}$, Hope Ring ${ }^{1 *}$, Michelle Fallon ${ }^{1}$ and Yaser Valiuddin ${ }^{2}$

\begin{abstract}
Background: No study to date has looked at the gender of emergency medicine (EM) physicians in the United States in relation to admission rates. This study seeks to investigate admission rates of adult patients treated by female vs male EM physicians, to identify whether a practice pattern bias exists.

Methods: This was a multicenter retrospective study of four community hospitals. Population: All patient encounters between July 1, 2016 and June 30, 2017. Outcome: We compared multiple benchmarks, including admission rates, patient acuity, length of stay, return visits, patient age, and years of practice using descriptive statistics and Pearson Correlation Coefficients.

Results: 171,762 encounters by $71 \mathrm{EM}$ physicians; 29 females, 42 males. Average admission rates: female 30.1\%, male 28.0\%, $p=.188$. Average encounters: female 2456, male 2394, $p=0.77$. Acuity: female 149.3, male 146.9, $p=.227$. Average length of stay (minutes): female 294.4, male 277.4, $p=.137$. Average patient age: female 50.9, male 50.2, $p=.457$. Median time of encounter: female 12.8, male 12.7, $p=.964$. Years of practice: female 16.2, male 19.1, $p=.274$. Average return visits per one thousand: female 8.5 , male $8.5, p=.864$. Secondary analysis of Pearson Correlation Coefficient of Significance; admission rate and length of stay: female $0.53, p=.0026$; male $0.76, p<.0001$. Admission rate and acuity: female $0.56, p=.0012$; male $0.76, p<.0001$. Admission rate and patient age: female $0.54, p=0.0018$; male $0.50, p=0.0003$.

Conclusion: No statistically significant difference exists between the admission rates of male and female emergency medicine physicians. The admission rate in both groups had the highest correlation with patients' age, acuity, and length of stay.
\end{abstract}

Keywords: Gender, Admission rate, Male, Female, Emergency physician, Admit

\section{Background}

Throughout every shift, an Emergency Medicine physician is making a plethora of decisions ranging from what pain medication to give a patient to whether a lifesaving intervention needs to be performed. Arguably one of the most important decisions a physician makes each

\footnotetext{
* Correspondence: Hope.Ring@stjoeshealth.org

'Department of Emergency Medicine, St. Mary Mercy Hospital, 36475 Five Mile, Livonia, MI 48154, USA

Full list of author information is available at the end of the article
}

shift is whether that patient needs to be admitted (inpatient or observation) or whether that patient is safe for discharge. A myriad of factors influence this decision, including but not limited to the patient's age, comorbid conditions, the support system at home, access to care, and the acuity of their condition. One study in Australia found strong evidence to suggest that personal sociodemographic and health characteristics are major drivers of preventable hospitalizations [1]. While another study found that avoidable hospitalization rates are lower in

C C The Author(s). 2020 Open Access This article is licensed under a Creative Commons Attribution 4.0 International License, which permits use, sharing, adaptation, distribution and reproduction in any medium or format, as long as you give appropriate credit to the original author(s) and the source, provide a link to the Creative Commons licence, and indicate if changes were made. The images or other third party material in this article are included in the article's Creative Commons licence, unless indicated otherwise in a credit line to the material. If material is not included in the article's Creative Commons licence and your intended use is not permitted by statutory regulation or exceeds the permitted use, you will need to obtain permission directly from the copyright holder. To view a copy of this licence, visit http://creativecommons.org/licenses/by/4.0/ The Creative Commons Public Domain Dedication waiver (http://creativecommons.org/publicdomain/zero/1.0/) applies to the data made available in this article, unless otherwise stated in a credit line to the data. 
areas with more primary care physicians-per-person according to bounded-area density measures [2]. Factors such as emergency department volume, time of patient presentation, and levels of senior support were also identified as non-clinical influences on the decision to admit rather than discharge patients [3]. We ask the question, does the gender of the treating physician also influence this decision?

Multiple studies across other specialties have noted that females and males can practice medicine differently. Females currently make up $50 \%$ of medical school graduates and 25\% of the Emergency Physician workforce [4]. Studies in Internal Medicine have looked at patient outcomes as a function of physician gender, finding that elderly patients treated by female internists had lower mortality and lower readmissions [5]. Another article reported that patients operated on by female surgeons had a statistically significant decrease in 30-day mortality [6]. One explanation for this difference was that female physicians are more likely to follow evidence-based guidelines [7]. It has also been noted in the literature that females employ a more "patient-centered" approach to patient care and engage in more preventative services for their patients than their male counterparts. Due to their communication style, patients of female physicians tend to disclose more biomedical information to them as well [8]. However, given these positive findings, there still exists a negative gender bias against female physicians in the workplace [9]. An example of such is a facility in Ontario that recently faced allegations for discriminatory hiring practices when it was found out that no female emergency physician was hired at the ED in 16 years [10]. Even after being hired, there exists gender disparity. Numerous papers have noted that female physicians are paid less than their male colleagues. Depending on the specialty, the gender pay gap can be anywhere from 16 to $37 \%$ [9]. This study seeks to provide evidence for dismissing such discrimination and could be used to further the arguments for gender equality and equal pay by demonstrating that no practice pattern bias exists based on gender alone.

No study to date has investigated practice patterns by analyzing a possible correlation between admission rates of adults in the US and the gender of treating emergency medicine physicians. Our study aims to discover whether there is an inherent gender bias in the decision to admit a patient with our hypothesis being that there will be no association between gender and admission rate.

\section{Methods}

We conducted a retrospective study analyzing all patient encounters from four hospitals over the July 1, 2016 to June 30, 2017 academic year. This study was approved by the Institutional Review Board with a waiver of consent.

This study was performed at four community-based hospitals that represent a varied patient population. The study institution and sister hospitals within the same health care system in southeast Michigan were selected based on the inclusion criteria of having more than one hundred inpatient beds and more than fifteen thousand ED visits per year. Primarily pediatric institutions were excluded. Trauma levels for each ED were certified by the American College of Surgeons. Geriatric emergency department designation was certified by the American College of Emergency Physicians. (Table 1).

Each ED was always staffed by emergency medicine board-certified or board-eligible physicians. All facilities were supported by residents or advanced practice providers. Advanced practice providers were defined as nurse practitioners or physician assistants.

Data was collected on emergency physicians who had at least 500 patient encounters per annum. Any patient encounter that resulted in a transfer or an elopement was excluded. Patient encounters for mental health diagnosis as determined by the International Classification of Diseases, Ninth Revision, Clinical Modification [ICD-9-CM] codes were also excluded, as the disposition plan for these patients was predicated upon strong discretion from the consulting psychiatric social worker evaluation and the resource availability at each separate study institution [11]. Physicians who worked majority in "fast-track" shifts, dedicated to seeing only the lowest acuity triaged patients (Emergency Severity Index 4-5) were excluded (Fig. 1) [12]. Using a data analytics registry we compiled physician metrics, benchmarks, and demographics; recording the

Table 1 Characteristics of Study Sites in 2016-2017

\begin{tabular}{lllll}
\hline Hospital & Hospital \#1 & Hospital \#2 & Hospital \#3 & Hospital \#4 \\
\hline Trauma Designation & Level 2 & Level 1 & No designation & No designation \\
Geriatric Designation & Level 1 & No designation & No designation & No designation \\
Total ED Beds & 51 & 65 & 19 & 20 \\
Total Hospital Beds & 304 & 537 & 136 & 133 \\
ED volume (per year) & 52,000 & 88,000 & 24,000 & 18,000 \\
Residents or APpa present & Yes & Yes & Yes & Yes \\
\hline
\end{tabular}

${ }^{\mathrm{a} A P P}$ Advanced practice providers (nurse practitioner or physician assistant) 


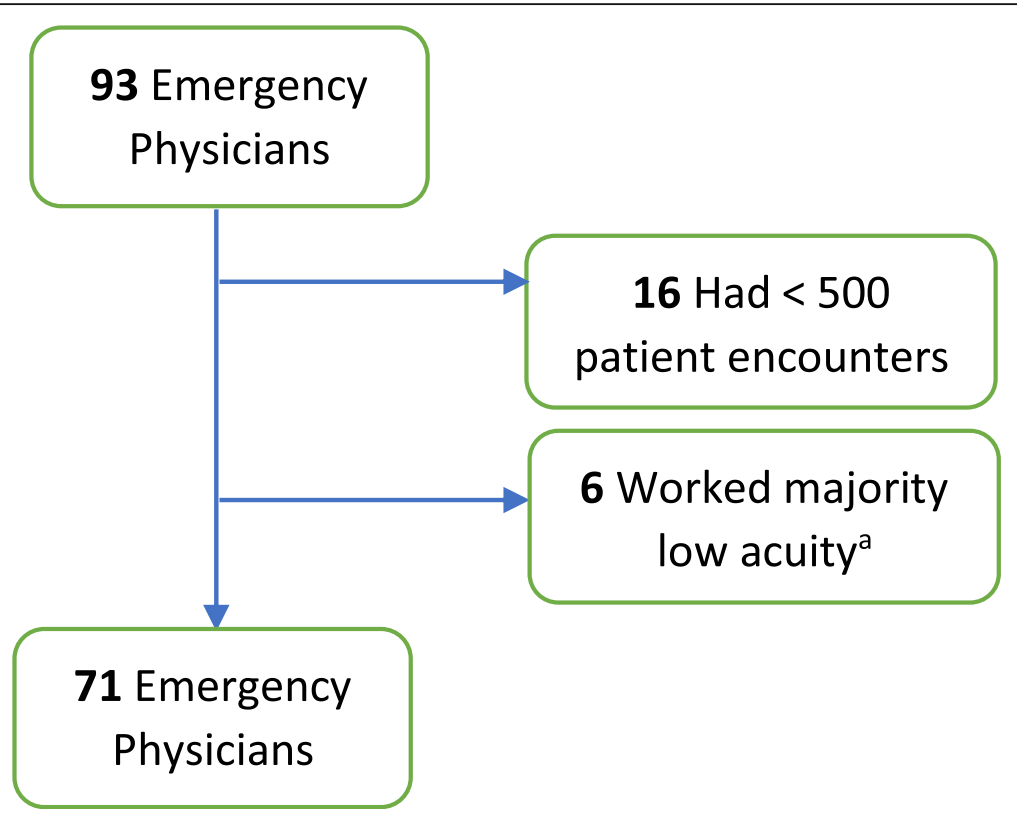

Fig. 1 Physician inclusion - exclusion criteria. ${ }^{a}$ Worked majority of shifts in low acuity section of department, seeing mostly low acuity triaged patients

admission rates, number of years of practice of physicians, average patient acuity treated by physicians, length of stay (LOS), patients age, number of encounters, number of male patients treated, number of female patients treated, time of encounters and total return visits after discharge from ED in $72 \mathrm{~h}$.

We then grouped the physician study population into male and female categories. Using descriptive statistics, we analyzed both groups. A secondary analysis was also performed to identify the interrelation of variables.

After the hospitals of interest were selected, we extracted data using an abstraction tool (Additional file 1), categorizing entries by physicians. The average acuity of patients seen by each physician was calculated based on the level of coding of the chart and associated critical care time billed. The level of coding was determined by billing experts from a revenue cycle and practice management company with greater than 30 years of experience, responsible for billing more than one hundred institutions, by reviewing physician charts and incorporating procedural codes. We weighted each level of coding and associated critical care time per the Medicare reimbursement schedule to calculate a composite score, which served as the average level of acuity of per patient seen by that physician [13]. To illustrate further, if a hypothetical physician only saw the lowest acuity patients, such as visits for suture removal, the physician would have a calculated composite score of 23; in contrast, if a hypothetical physician only saw the highest acuity patients, such as acute respiratory failure, the physician would have a resultant composite score of 236 .
The average length of stay was recorded in minutes per patient encounter. Time was started upon triage registration of the patient and ended when the determined disposition order was placed. Demographics of patient encounters included average patient age at the time of encounter and gender of patients treated. Benchmark data included average return visits per one thousand patient encounters and the total number of patients encounters over the study period per physician. Ancillary information such as years of practice and time of encounter were also recorded and assessed to determine if these variables were potential confounders. Years of practice were calculated by years removed from the date of graduation of medical school. Time of encounter was recorded using a military time scale and a median time of encounter was determined for each physician. Physician data, including physician age, was aggregated by querying Doximity, a comprehensive online database of US physicians that assembles networking services for US physicians through data partnerships, including the American Board of Medical Specialties, state licensing boards, and collaborating hospitals and medical schools. Each physician was then classified as either male or female. After database finalization, unadjusted differences between genders were compared using t-tests and chi-square tests, depending on the variable distribution. The t-tests were performed using the Satterthwaite adjustment for unequal variances. Adjusted estimates were not performed, as no significant gender differences emerged on the possible confounding variables. 
The primary outcome was to assess differences in admission rates between male and female emergency physicians. The admission rate is defined as the portion of encounters that resulted in admission to the hospital. Admission includes patients who were dispositioned to an observation unit, inpatient unit, or emergency surgery. Secondary outcomes measured statistical differences between the two genders for the other study variables. The tertiary analysis was conducted to assess the correlation between average patient characteristics variables and admission rates at the physician level. As this was a tertiary analysis, no regression adjustments were performed.

The cut-off for statistical significance was set at $p<$ 0.05 (two-tailed). The tertiary analysis was determined by comparing each variable with the admission rate using Pearson's $r$. All analyses were performed in SAS statistical software (SAS, version 9.4, SAS Institute Inc., Cary, NC).

\section{Results}

Overall, there were 171,762 ED patient encounters, treated by 71 total physicians, of whom, 29 (41\%) were female and $42(59 \%)$ male. The average admission rate for female physicians was $30.1 \%$ (range 19.3-43.8\%) and male physicians had an average admission rate of $28.0 \%$ (range 14.3-40.6), which was not statistically significant (Table 2).

Table 2 displays the remaining variables that were analyzed regarding the patient-physician encounters, as well as their respective $t$-tests. No statistically significant difference was found for any of the patient demographics. The acuity of patients seen, average patient encounter LOS, and the average number of return visits in $72 \mathrm{~h}$ per one thousand patient encounters were not statistically different for either group. Both physician groups had a

Table 2 Gender averages

\begin{tabular}{|c|c|c|c|}
\hline Variables & Female $(n=30)$ & $\begin{array}{l}\text { Male } \\
(n=47)\end{array}$ & $\begin{array}{l}\text { T test } \\
(p-\text { value })\end{array}$ \\
\hline$\overline{\text { Acuity }^{a}}$ & 149.3 & 146.9 & 0.227 \\
\hline Length of stay (minutes) & 294.4 & 277.4 & 0.137 \\
\hline $\begin{array}{l}\text { Return visits per } 1000 \\
\text { encounters (patients) }\end{array}$ & 8.4 & 8.5 & 0.864 \\
\hline Patient age (years) & 50.9 & 50.2 & 0.457 \\
\hline Years of practice & 16.2 & 19.1 & 0.274 \\
\hline $\begin{array}{l}\text { Number of female patients } \\
\text { (per annum) }\end{array}$ & 1074 & 1051 & 0.804 \\
\hline $\begin{array}{l}\text { Number of male patients } \\
\text { (per annum) }\end{array}$ & 1382 & 1343 & 0.752 \\
\hline Total patients (per annum) & 2456 & 2394 & 0.770 \\
\hline Median time of encounter ( $24 \mathrm{~h}$ ) & 30.1 & 28.0 & 0.188 \\
\hline
\end{tabular}

${ }^{a}$ Based on weighted average of billing codes per Medicare reimbursement (Range 23-236, with 236 as most critical) similar composition of career experience in terms of years of practice and also were similar in the volume of patients seen. The gender breakdown of the patient census treated by both groups and median time of patient encounter was equivalent in both groups as well. The. These results suggest that males and females saw similar types of patients.

From all the variables that were examined, admission rates by both physician groups were found to have the strongest positive correlation with acuity level of patients: male 0.76, $p<0.0001$ and female 0.56, $p=0.0012$. Also, both groups had a strong positive correlation between admission rate and length of stay: male 0.76 , $p<0.0001$ and female 0.53, $p=0.0026$. There was a moderate correlation in both groups between admission rate and the patient age: male $0.55, p=0.0018$, and female $0.50, p=0.0003$.

\section{Discussion}

In this study, no gender practice pattern bias was found regarding the admission rate. This study is the first of its kind in the US. International data in different populations has suggested a possible correlation previously. One study conducted at a single pediatric ED in Canada, found no correlation, while another study conducted at a single adult ED in Spain found female physicians had a higher admission rate [14]. This is the only multi-center study on the topic and the largest study to date. Looking at many measurable factors and recordable characteristics, we found there to be no unadjusted statistical difference between the admission rate of female and male EM physicians, while the patients' characteristics were similar between genders. This provides evidence that both groups make disposition decisions based on a patient's clinical condition and situation. This can be noted by the Pearson correlation coefficients, which found a positive correlation in both groups between admission rates and acuity of patients, LOS, and patient age. Patients who were admitted to the hospital tended to be sicker, older in age, and have a longer LOS in the Emergency Department.

Our study sample analyzed data from four different institutions to assess a varied population of physicians and patient encounters. Previous literature, Miro et al., suggested that female emergency physicians admitted a statistically significant larger percentage of patients [15], differing from the results we found. One possible explanation is that Miro et al., was a single hospital study with only 50 providers enrolled. As with any study with small sample size, any discrepancy of a single physician could have profound effects on the study population. In studying a larger population of physicians, we found that the difference quoted in the prior study did not correlate with our results. 
For the secondary outcomes analysis, we also recorded physician data on average patient return visits to investigate the possible correlation with the admission rate, which is novel to this study. Moreover, if a statistically significant difference in admission rate was found, there would have been an analogous difference in patient return visits. No such pattern was identified. Also, we found no gender disparity in the rate of return visits, as well as no correlation between the admission rate and return visit rate per gender group. When discussing return visits, caution is needed to interpret the results in the appropriate context. Many factors can account for a patient returning to the ED within $72 \mathrm{~h}$ of discharge; including expected reasons such as resource availability or need for serial exams. Average return visits are not explicit surrogate measures of quality of care delivered upon initial visit, and this secondary analysis further adds to the evidence [16-18]. Further studies are needed for a robust analysis of patient outcomes concerning admission rates and appropriate disposition planning.

Our overall finding of no association between gender and admission rate, as well as additional findings of no association between gender and volume of patients seen, acuity of patients treated, LOS, years of practice, time of encounters, or return visits, all add critical information to the conversation of evaluating gender disparities of practicing emergency medicine physicians. For instance, gender disparities have previously been reported among physician salaries. Watts et al. reported that between full-time EM faculty, females were paid 10 to $13 \%$ less than their male counterparts [19]. Madsen et al. validated this difference, reporting that women on average earned $\$ 19,000$ less than their male colleagues, working a similar number of clinical hours; concluding that significant disparities continue to exist in representation, rank, and salaries of academic physicians [20]. Some of the reasons for this difference is theorized to be attributed to gender differences in negotiation, due to perceived conscious and unconscious biases, along with differences in opportunities to advance career and receive promotions [21, 22].

No practice pattern bias was identified in our study using objective measures, which further sheds light on gender studies of practicing emergency medicine physicians. Having this evidence, further studies can be conducted exploring gender disparities that are important in identifying unknown biases.

There are some limitations to this study. The sample of physicians studied were all employed by the same corporation, practicing within the same hospital system and geographic area. Consequently, practice patterns could be affected by hospital-wide protocols, clinical pathways, and guidelines. Although this limitation would similarly affect each group, making intergroup comparisons reliable, specific rates and characteristic information from this study may not be generalizable nationally. Second, the acuity of patients was determined using billing codes based on charting. Billing experts optimized the medical charts for the level of billing but cannot compensate for omitted data from medical charts resulting in a lower level of billing when in fact, acuity of the patient could be higher. Lastly, the gender of physicians and patients were recorded in categorical variables defined as female or male; therefore, no further investigation could be conducted about transgender or nonbinary individuals.

\section{Conclusion}

In summary, there is no statistically significant difference between the admission rates of male and female emergency medicine physicians. For both groups, the admission rate had the highest correlation with patients' age, acuity, and length of stay.

\section{Supplementary information}

Supplementary information accompanies this paper at https://doi.org/10. 1186/s12873-020-00349-4.

\section{Additional file 1}

\section{Abbreviations}

ED: Emergency Department; EM: Emergency Medicine; ICD-9-

CM: International Classification of Diseases, Ninth Revision, Clinical Modification; LOS: Length of stay; SAS: Statistical Analysis Software

\section{Acknowledgments}

Not applicable.

\section{Authors' contributions}

HV designed the study, performed the literature review, assisted with data collection, statistical analysis, and wrote the manuscript. MF assisted with the literature review, data analysis, and writing the manuscript. $Y$ assisted with data interpretation and writing the manuscript. HR mentored research, ensured IRB compliance, contributed to the writing and critical revision. All authors have read and approved this manuscript and submission.

\section{Funding}

There was no funding for this study.

\section{Availability of data and materials}

The datasets generated and/or analyzed during the current study are not publicly available due to individual privacy but are available from the corresponding author on reasonable request.

Ethics approval and consent to participate

This study was approved by the St. Joseph Mercy Health System Institutional Review Board with a waiver of informed consent.

Consent for publication

Not applicable.

Competing interests

The authors declare that they have no competing interests. 


\section{Author details}

'Department of Emergency Medicine, St. Mary Mercy Hospital, 36475 Five Mile, Livonia, MI 48154, USA. Edward Via College of Osteopathic Medicine, 2265 Kraft Drive, Blacksburg, VA 24060, USA.

Received: 19 January 2020 Accepted: 24 June 2020

Published online: 01 July 2020

\section{References}

1. Falster MO, Jorm LR, Douglas KA, Blyth FM, Elliott RF, Leyland AH. Sociodemographic and health characteristics, rather than primary care supply, are major drivers of geographic variation in preventable hospitalizations in Australia. Med Care. 2015;53(5):436-45. https://doi.org/10. 1097/MLR.0000000000000342.

2. Daly MR, Mellor JM, Millones M. Do Avoidable Hospitalization Rates among Older Adults Differ by Geographic Access to Primary Care Physicians? Health Serv Res. 2018;53(Suppl 1):3245-64. https://doi.org/10.1111/14756773.12736

3. Pope I, Burn H, Ismail SA, Harris T, McCoy D. A qualitative study exploring the factors influencing admission to hospital from the emergency department. BMJ Open. 2017;7(8):e011543. Published 2017 Aug 29. https:// doi.org/10.1136/bmjopen-2016-011543.

4. Emergency Medicine Workforce Needs More Women Physicians. ACEP Now. Available from: https://www.acepnow.com/article/emergency-medicineworkforce-needs-women-physicians/. Accessed 25 Jan 2019.

5. Tsugawa $Y$, Jena AB, Figueroa JF, Orav EJ, Blumenthal DM, Jha AK. Comparison of hospital mortality and readmission rates for Medicare patients treated by male vs female physicians. JAMA Intern Med. 2017; 177(2):206-13.

6. Wallis CJ, Ravi B, Coburn N, Nam RK, Detsky AS, Satkunasivam R. Comparison of postoperative outcomes among patients treated by male and female surgeons: a population based matched cohort study. BMJ. 2017; 359: 4366.

7. Wallis CJD, Ravi B, Coburn N, Nam RK, Detsky AS, Satkunasivam R. Comparison of postoperative outcomes among patients treated by male and female surgeons: a population based matched cohort study. The BMJ. British Medical Journal Publishing Group; 2017. Available from: https:/www. bmj.com/content/359/bmj.j4366. Accessed 2 Feb 2019.

8. Roter L. Physician gender effects in medical communication. JAMA. American Medical Association; 2002. Available from: https://jamanetwork. com/journals/jama/fullarticle/195191. Accessed 3 Feb 2019.

9. Krzyzaniak SM, Gottlieb M, Parsons M, Rocca N, Chan TM. What emergency medicine rewards: is there implicit gender Bias in National Awards? Ann Emerg Med. 2019;74(6):753-8. https://doi.org/10.1016/j.annemergmed.2019. 04.022 Epub 2019 Jun 20. PubMed PMID: 31229389.

10. Glauser, W. Ontario emergency room chief who hired no women for 16 years resigns amid discrimination probe. The Globe and Mail. 21 February 2019. Available from: https://www.theglobeandmail.com/canada/ investigations/article-ontario-emergency-room-chief-who-hired-no-womenfor-16-years-resigns/. Accessed 30 March 2020.

11. ICD - ICD-9-CM - International Classification of Diseases, Ninth Revision, Clinical Modification. Centers for Disease Control and Prevention. Centers for Disease Control and Prevention; 2015. Available from: https:/www.cdc. gov/nchs/icd/icd9cm.htm. Accessed 19 Feb 2019.

12. Gilboy N, Tanabe P, Travers DA, Rosenau AM, Eitel DR. Emergency Severity Index, Version 4: Implementation Handbook. (Publication A, ed.). Rockville: Agency for Healthcare Research and Quality; 2018. https:/wwww.ahrq.gov/ sites/default/files/wysiwyg/professionals/systems/hospital/esi/esihandbk.pdf. Accessed 23 Feb 2019.

13. Fee Schedules - General Information. Centers for Medicare \& Medicaid Services. Available from: https://www.cms.gov/medicare/medicare-fee-forservice-payment/feeschedulegeninfo/index.html. Accessed 24 Feb 2019.

14. Gaucher N, Bailey B, Gravel J. Impact of physicians' characteristics on the admission risk among children visiting a pediatric emergency department. Ped Emerg Care. 2012;28(2):120-4.

15. Miró Ò. Emergency physician sex and emergency department resource use. Eur J of Emerg Med. 2017;24(4):277-83.

16. Sills MR, Macy ML, Kocher KE, Sabbatini AK. Return visit admissions may not indicate quality of emergency Department Care for Children. Acad Emerg Med. 2018;25(3):283-92.
17. Abualenain J, Frohna WJ, Smith M, Pipkin M, Webb C, Milzman D, Pines JM. The prevalence of quality issues and adverse outcomes among 72-hour return admissions in the emergency department. J Emerg Med. 2013;45(2): 281-8.

18. Sabbatini AK, Kocher KE, Basu A, Hsia RY. In-hospital outcomes and costs among patients hospitalized during a return visit to the emergency department. JAMA. 2016;315(7):663-71.

19. Watts SH, Promes SB, Hockberger R. The Society for Academic Emergency Medicine and Association of Academic Chairs in emergency medicine 2009-2010 emergency medicine faculty salary and benefits survey. Acad Emerg Med. 2012;19(7):852-60.

20. Madsen TE, Linden JA, Rounds K, Hsieh YH, Lopez BL, Boatright D, Garg N, Heron SL, Jameson A, Kass D, Lall MD. Current status of gender and racial/ ethnic disparities among academic emergency medicine physicians. Acad Emerg Med. 2017;24(10):1182-92.

21. Li CJ, Syue YJ, Tsai TC, Wu KH, Lee CH, Lin YR. The impact of emergency physician seniority on clinical efficiency, emergency department resource use, patient outcomes, and disposition accuracy. Med. 2016;95(6):e2706.

22. Butkus R, Serchen J, Moyer DV, Bornstein SS, Hingle ST. Achieving gender equity in physician compensation and career advancement: a position paper of the American College of Physicians. Annals of Internal Medicine. American College of Physicians; 2018. Available from: https://annals.org/aim/ fullarticle/2678630/achieving-gender-equity-physician-compensation-careeradvancement-position-paper-american. Accessed 12 Feb 2019.

\section{Publisher's Note}

Springer Nature remains neutral with regard to jurisdictional claims in published maps and institutional affiliations.

\section{Ready to submit your research? Choose BMC and benefit from:}

- fast, convenient online submission

- thorough peer review by experienced researchers in your field

- rapid publication on acceptance

- support for research data, including large and complex data types

- gold Open Access which fosters wider collaboration and increased citations

- maximum visibility for your research: over $100 \mathrm{M}$ website views per year

At BMC, research is always in progress.

Learn more biomedcentral.com/submissions 